\section{Chiari malformation Type 1 and atlantoaxial instability: a letter from the Pediatric Craniocervical Society}

TO THE EDITOR: In his article, ${ }^{3}$ Dr. Atul Goel examines the underlying cause and treatment of Chiari malformation Type I (CM-I) in 65 patients at his institution in Mumbai, India (Goel A: Is atlantoaxial instability the cause of Chiari malformation? Outcome analysis of 65 patients treated by atlantoaxial fixation. J Neurosurg Spine 22:116-127, February 2015). All were treated with a surgical technique to fuse the atlas and axis without foramen magnum decompression or intradural exploration. Sixtythree of the patients had favorable outcomes, 1 failed to improve after surgery, and 1 died from a vertebral artery injury. The atlantoaxial fusions were performed on the basis of Dr. Goel's novel classification scheme, with or without any radiographic evidence of instability of the joint. At the conclusion of the paper, Dr. Goel suggests that all patients with CM-I be treated with this technique.

After carefully reviewing the paper, we believe that adopting this approach for all patients with CM-I is wrong and potentially dangerous.

Dr. Goel's patient population was complex, with a high representation of craniovertebral junction anomalies and large syrinxes, atypical of the general patient population with CM-I. Basilar invagination was identified in 46 of 65 patients and syringomyelia in 55 of 65 patients. Only 11 of 65 patients were "independent and normally functioning," with 12 of 65 "unable to walk and dependent for all activities." This particular patient group is more advanced in their symptoms and more complex than those who are typically seen at other centers. Historically, these patients are difficult to successfully treat and do not represent the majority of patients with CM-I. Authors from multiple centers worldwide have reported excellent outcomes for patients with CM-I who are treated using foramen magnum decompression and dural opening without atlantoaxial fusion. ${ }^{1,5-7}$ Therefore, the suggestion that we abandon these traditional operative techniques is premature.

Defining instability in these complex patients can be challenging. It is well known and accepted that occipitocervical fusion is necessary in a small subset of complex patients with CM-I, ${ }^{2}$ but applying these techniques to all patients with CM-I, especially those without evidence of spinal instability, is illogical. Dr. Goel's novel classification scheme of "atlantoaxial dislocation" has not been confirmed, standardized, or validated. One of Dr. Goel's specific assertions is that one can restrict fusion to the atlantoaxial level and have the same effect as an occipitocervical fusion. This argument is undermined by the fact that, as pointed out in Dr. Jea's editorial, ${ }^{4}$ at least 33 of 65 patients had occipitalization of the atlas, and thus essentially turning Goel's atlantoaxial fusions into the biomechanical equivalent of an occipitocervical fusion. Five of the 6 illustrated cases in the paper demonstrate this point.

To convince others to adopt his novel approach, Dr. Goel will need to confirm his findings with rigorous postoperative assessment. In his paper, only 11 of 65 patients had postoperative MRI, and 5 of 11 apparently showed no syrinx change. Although 1 death was reported, an additional patient had "clear evidence of a posterior circulation infarct related to an intraoperative vertebral artery injury." It is not clear whether this patient was in the group that improved postoperatively.

Many questions remain unanswered: 1) What specific criteria were used to pick the patients for atlantoaxial fusion? 2) Why did patients undergo fusion without traditional evidence of atlantoaxial instability? 3) What clinical and radiographic criteria were used to define success? 4) Applying Dr. Goel's methodology and conclusions, how does he explain the excellent reported outcomes in the thousands of pediatric and adult patients with CM-I who underwent foramen magnum decompression without atlantoaxial fusion?

It is clear that there is a small subpopulation of patients with CM-I and significant craniovertebral junction anomalies that may benefit from an occipitocervical fusion when instability is present; however, until Dr. Goel demonstrates that his novel classification system and clinical management are appropriate and applicable to the majority of patients with CM-I, universal application of his strategy of atlantoaxial fusion without foramen magnum decompression to the general CM-I population is unwarranted and may be potentially harmful.

Douglas L. Brockmeyer, MD University of Utah, Primary Children's Hospital, Salt Lake City, UT

W. Jerry Oakes, MD

Curtis Rozzelle, MD

James Johnston, MD

Brandon G. Rocque, MD, MS

University of Alabama, Birmingham, AL

Richard C. E. Anderson, MD

Neil Feldstein, MD

Columbia University Medical Center, New York, NY

Jonathan Martin, MD

Connecticut Children's Hospital, Hartford, CT

Gerald F. Tuite, MD

Luis Rodriguez, MD

University of South Florida/All Children's Hospital, St. Petersburg, FL 
Nicholas Wetjen, MD

Mayo Clinic, Rochester, MN

Phillip Aldana, MD

Dave Pincus, MD

University of Florida at Jacksonville, Jacksonville, FL

Phillip Storm, MD

Children's Hospital of Philadelphia, Philadelphia, PA

Mark R. Proctor, MD

Boston Children's Hospital, Boston, MA

Sean Lew, MD

Children's Hospital of Wisconsin, Milwaukee, WI

\section{DISCLOSURE}

The authors report no conflict of interest.

\section{References}

1. Batzdorf U, McArthur DL, Bentson JR: Surgical treatment of Chiari malformation with and without syringomyelia: experience with 177 adult patients. J Neurosurg 118:232-242, 2013

2. Bollo RJ, Riva-Cambrin J, Brockmeyer MM, Brockmeyer DL: Complex Chiari malformations in children: an analysis of preoperative risk factors for occipitocervical fusion. J Neurosurg Pediatr 10:134-141, 2012

3. Goel A: Is atlantoaxial instability the cause of Chiari malformation? Outcome analysis of 65 patients treated by atlantoaxial fixation. J Neurosurg Spine 22:116-127, 2015

4. Jea A: Editorial: Chiari malformation I surgically treated with atlantoaxial fixation. J Neurosurg Spine 22:113-115, 2015

5. Klekamp J: Surgical treatment of Chiari I malformationanalysis of intraoperative findings, complications, and outcome for 371 foramen magnum decompressions. Neurosurgery 71:365-380, 2012

6. Lee A, Yarbrough CK, Greenberg JK, Barber J, Limbrick DD, Smyth MD: Comparison of posterior fossa decompression with or without duraplasty in children with Type I Chiari malformation. Childs Nerv Syst 30:1419-1424, 2014

7. Tubbs RS, Beckman J, Naftel RP, Chern JJ, Wellons JC III, Rozzelle CJ, et al: Institutional experience with 500 cases of surgically treated pediatric Chiari malformation Type I. J Neurosurg Pediatr 7:248-256, 2011

\section{Response}

It is clear from this letter (and from previous correspondences) that my article has been received with great interest. While I am convinced about the various theories I proposed and my continuing clinical experience reaffirms my belief, the letter provides me with an additional opportunity to present my viewpoint to the readers and to the various experienced and respected neurosurgeons listed in the letter.

At variance with the decades-old concept that $\mathrm{CM}$ is a pathological entity and an event related to embryonic dysgenesis, my article suggests that CM could be Nature's protective phenomenon and that tonsillar herniation simulates an air bag. ${ }^{11}$ The air bag is positioned to cushion the critical craniocervical cord against impending pinching between bones in the event of local instability. The instability seems to be recognized by Nature, protective acts are initiated early in life, and the clinical manifestations are delayed. We had earlier hypothesized that a short neck, torticollis, platybasia, Klippel-Feil anomalies, assimilation of the atlas, secondary spondylotic changes, and several other musculoskeletal events associated with basilar invagination may not be congenital anomalies, but rather Nature's protective responses in the face of atlantoaxial instability. Atlantoaxial fixation has resulted in the reversal of several of the above-mentioned physical abnormalities in the immediate postoperative period. ${ }^{26,30}$ We also mentioned that there is potential for the reversal of all musculoskeletal events including bone fusions. ${ }^{30} \mathrm{We}$ now observe that both $\mathrm{CM}$ and syringomyelia in the presence or absence of basilar invagination are a continuum of the same phenomenon and are natural events that are protective. While CM simulates an air bag, syringomyelia is a natural self-neural destructive process that works in the greater interest of the body. Both CM and syringomyelia should be respected as protective, not as pathological events, and should be treated as such..$^{11,13}$

Our experience in dealing with and manually handling unstable atlantoaxial and subaxial spinal facets is more than 25 years long. ${ }^{1-7,10,15-20,22-29,31-36}$ We have treated over 1300 cases by atlantoaxial fixation..$^{22,26}$ Because of this unique opportunity, we are able to identify the presence or absence of instability rather easily by assessing the local stability situation during an operation by manual bone handling. Atlantoaxial instability has traditionally been diagnosed by assessing the atlantodental interval and by observing its alteration on dynamic imaging. Although the concept of "facetal" instability, as proposed by us, is neither established nor validated, it appears to be a phenomenon that opens up space for a fresh understanding of the subject. ${ }^{8} 9$ The fact that instability can be assessed by facetal alignments can have a great impact on understanding the dynamics of the region and in conceptualizing the treatment options. In cases with basilar invagination, we had earlier identified anterior dislocation of the facet of the atlas over the facet of the axis and labeled it atlantoaxial listhesis, a situation similar to lumbosacral listhesis. ${ }^{10,17,19,36}$ In this situation the atlantodental interval increases, and there is direct indentation of the neural structures by the odontoid process. The clinical presentation in such cases is rather acute, and chronic musculoskeletal and neural alterations are not the hallmark of such cases. We labeled this type of facetal instability as Type I dislocation. We further identified instability of the atlantoaxial region as manifested by posterior dislocation of the facet of the atlas over the facet of the axis (Type II). We also identified Type III atlantoaxial facetal instability, wherein the facets are in alignment but the instability is identified by corroborative clinical and radiological evidence and observed only by direct intraoperative handling of the facets. We called such instability "central" or "axial" atlantoaxial instability. The atlantodental interval is unaffected in both Types II and III, and direct compression of the neural structures by the odontoid process is not evident. Moreover, instability in these cases is rather subtle, although it is definite and pathological. Essentially, Type II and Type III atlantoaxial facetal dislocations are associated with longstanding or chronic events such as Group B basilar invagination and/ or $\mathrm{CM}$ with or without the association of syringomyelia.

In the year 2004, we demonstrated that the atlantoaxial joint in select cases of basilar invagination (Group 
A) is neither fixed nor fused, is not only mobile but hypermobile, and, more importantly, is reducible by manual distraction, reduction, and fixation. ${ }^{17}$ This concept was at variance with an age-old concept that basilar invagination is a "fixed" anomaly. The concept radically modified and revolutionized the treatment of the entity from a decompression operation by transoral surgery to craniovertebral realignment by a "posterior-only" method of treatment. We had earlier recommended this form of treatment only for Group A basilar invagination. In the same article, we suggested that atlantoaxial joints are fixed or fused in Group B cases and recommended foramen magnum decompression for such cases. As our experience in the subject grew, we observed that atlantoaxial instability is the defining feature in both Group A and B cases, even when it is not demonstrated or identified by conventional radiological parameters. The instability in Group B cases may be Type II or Type III facetal instability. It is now clear to us that atlantoaxial fixation forms the mode of treatment for both Group A and B cases. Any form of decompressive operation, either by transoral surgery or by foramen magnum decompression, is neither indicated nor a rational form of surgical therapy in such cases.

The instability in such cases is at the atlantoaxial joint. There is no occipitoatlantal instability. On the other hand, frequently there can be assimilation of the atlas into occipital bone. Any surgery that involves occipital bone in the fixation and a normal occipitoatlantal joint in the construct is suboptimal and will severely restrict head and neck movements. ${ }^{12,14}$ We clearly understand that exposure of the facets of the atlas and axis is not a simple or straightforward surgery, particularly for those not conversant with the region. Exposure of the region is significantly more difficult in the presence of basilar invagination, where bone and vascular structural abnormalities can be profound. Assimilation of the atlas signals a rostral location of the facets and the consequent difficulty in surgical exposure. Despite our experience in exposure of the lateral masses, we did have issues with vertebral artery injury and the related posterior circulation infarct in 1 case, as discussed in our article. However, we are convinced that if the atlantoaxial joint can be opened, articular cartilage can be denuded, bone graft can be introduced into the joint, and facetal screw fixation can be done under direct vision, the fixation is far more robust and the construct is remarkably stable and segmental. Occipital squama for screw fixation can be used in such cases, particularly when there is assimilation of the atlas and the surgeon is not conversant with exposure of the region of the facets of the atlas and axis. However, from my experience in the subject, I can say with a great deal of confidence that occipitocervical fixation provides a suboptimal form of stabilization of the region. For several years now, we have completely abandoned inclusion of the occipital bone (even in cases with assimilation of the atlas) and subaxial vertebrae in the fixation construct. We rarely do such long fixations in pediatric cases having the syndromic form of multijoint instability, in cases with tumors, or in cases with craniovertebral junction tuberculosis and rheumatoid arthritis. Such cases are not the subject of our present analysis.

In the year 1997, we divided basilar invagination into 2 groups on the basis of the absence (Group I) or presence (Group 2) of CM. ${ }^{19}$ While we recommended transoral decompression for Group I cases, we recommended foramen magnum decompression in Group II cases. This recommendation was based on our understanding that reduced posterior cranial fossa volume was probably the cause of CM. However, our current evaluation suggests that posterior fossa volume is not reduced, and the superior vermis and part of the cerebellum are atrophied in these cases, suggesting that the theory of a large bulk of cerebellum in a relatively small posterior fossa is not applicable. ${ }^{21}$ Our current concept is that atlantoaxial instability is the prime pathogenetic factor for all cases with basilar invagination. Accordingly, atlantoaxial fixation is the best mode of surgical treatment.

Chiari malformation with or without the association of bone anomalies at the craniovertebral junction and basilar invagination are a continuum of the same pathology. Atlantoaxial instability is the cause of symptoms and structural malformation, and atlantoaxial fixation is the treatment. Foramen magnum decompression is not a rational form of treatment.

The issues of a different patient population and a discrete form of CM encountered by us in our rather poor Indian population compared with the patients seen by authors of the letter can be discussed. It is possible that we encounter our patients relatively late in their disease process, while Brockmeyer et al. may be able to diagnose their patients with only subtle neurological signs and symptoms. Despite the differences, the general disease process cannot be different in the 2 patient subgroups.

To answer the questions posed by Brockmeyer et al. we have to state that 1) the presence of CM is a definitive indicator of atlantoaxial instability. Atlantoaxial fixation should be done. Foramen magnum decompression is not indicated and in the long run is counterproductive. 2) Atlantoaxial facetal instability can be gauged not only by an altered atlantodental interval but also by facetal malalignment. Even if the facets are in alignment, the presence of $\mathrm{CM}$ is an indicator of central or axial instability. 3) The success of treatment is gauged, more importantly, by clinical recovery. In our experience, in cases where atlantoaxial fixation has been done, recovery is far quicker, more effective, and longstanding than in the cases where foramen magnum decompression has been done. 4) In our article, we mentioned that postoperative recovery following foramen magnum decompression is akin to recovery for the car driver after the deflation of a full air bag. However, in the long run such an operation is counterproductive.

The validity of our concept is obvious from the following: 1) remarkable clinical improvement in a majority of cases where the operation was aimed at atlantoaxial fixation and segmental arthrodesis and where no midline bone or dural decompression was performed, 2) improvement in clinical symptoms in cases where the foramen magnum decompression procedure had been done earlier and had failed, and 3) reduction in the size of the syrinx and the reversal of tonsillar herniation without any direct handling.

The authors of the letter will agree that for the thousands of patients who have improved following foramen magnum decompression, there is another thousand who 
have not improved or whose condition has worsened after surgery. The literature mentions an approximately $20 \%-$ $30 \%$ failure rate for foramen magnum surgery. There are several reports of patients who, after the procedure of foramen magnum decompression and duraplasty, have radiological regression of the tonsillar herniation, as well as a reduction in the syrinx, but have clinical deterioration.

What could be the reason for the delayed worsening in patients with $\mathrm{CM}$ in whom foramen magnum decompression has been performed? I am wondering what the authors will do if foramen magnum decompression surgery has failed.

It is our belief that, as in 2004 when our article set a background for relegating transoral surgery into the realm of history, ${ }^{17}$ our current article and our other related articles have the potential to serve as the foundation for subjecting foramen magnum decompression surgery for basilar invagination, "irreducible" atlantoaxial dislocation, and CMs with or without any bone anomaly to the same fate of extinction.

Atul Goel, MCh

K.E.M. Hospital and Seth G. S. Medical College, Parel, Mumbai, India

\section{References}

1. Goel A: Atlantoaxial joint jamming as a treatment for atlantoaxial dislocation: a preliminary report. Technical note. J Neurosurg Spine 7:90-94, 2007

2. Goel A: Basilar invagination, Chiari malformation, syringomyelia: a review. Neurol India 57:235-246, 2009

3. Goel A: Cervical ganglion 2 (CG2) neurectomy: a window to the atlantoaxial joint. World Neurosurg 78:78-79, 2012

4. Goel A: Craniovertebral anomalies: role for craniovertebral realignment. Neurol India 52:427-429, 2004

5. Goel A: Craniovertebral junction instability: special reference to paediatric age group. Adv Tech Stand Neurosurg 40:215-259, 2014

6. Goel A: Double insurance atlantoaxial fixation. Surg Neurol 67:135-139, 2007

7. Goel A: Facet distraction-arthrodesis technique: Can it revolutionize spinal stabilization methods? J Craniovertebr Junction Spine 2:1-2, 2011

8. Goel A: Facetal alignment: Basis of an alternative Goel's classification of basilar invagination. J Craniovertebr Junction Spine 5:59-64, 2014

9. Goel A: Goel's classification of atlantoaxial "facetal" dislocation. J Craniovertebr Junction Spine 5:3-8, 2014

10. Goel A: Instability and basilar invagination. J Craniovertebr Junction Spine 3:1-2, 2012

11. Goel A: Is Chiari malformation nature's protective "airbag"? Is its presence diagnostic of atlantoaxial instability? J Craniovertebr Junction Spine 5:107-109, 2014

12. Goel A: Is inclusion of the occipital bone necessary/countereffective for craniovertebral junction stabilization? J Craniovert Jun Spine 6:102-104, 2015

13. Goel A: Is syringomyelia pathology or a natural protective phenomenon? J Postgrad Med 47:87-88, 2001

14. Goel A: Occipitocervical fixation: is it necessary? J Neurosurg Spine 13:1-2, 2010

15. Goel A: Progressive basilar invagination after transoral odontoidectomy: treatment by atlantoaxial facet distraction and craniovertebral realignment. Spine (Phila Pa 1976) 30:E551-E555, 2005

16. Goel A: Screws, facets, and atlantoaxial instability. World Neurosurg 80:514-515, 2013

17. Goel A: Treatment of basilar invagination by atlantoaxial joint distraction and direct lateral mass fixation. J Neurosurg Spine 1:281-286, 2004

18. Goel A, Achawal S: The surgical treatment of Chiari malformation association with atlantoaxial dislocation. Br J Neurosurg 9:67-72, 1995

19. Goel A, Bhatjiwale M, Desai K: Basilar invagination: a study based on 190 surgically treated patients. J Neurosurg 88:962-968, 1998

20. Goel A, Desai K: Surgery for syringomyelia: an analysis based on 163 surgical cases. Acta Neurochir (Wien) 142:293-302, 2000

21. Goel A, Desai K, Bhatjiwale M, Muzumdar DP: Basilar invagination and Chiari malformation associated with cerebellar atrophy: report of two treated cases. J Clin Neurosci 9:194-196, 2002

22. Goel A, Desai KI, Muzumdar DP: Atlantoaxial fixation using plate and screw method: a report of 160 treated patients. Neurosurgery 51:1351-1357, 2002

23. Goel A, Figueiredo A, Maheshwari S, Shah A: Atlantoaxial manual realignment in a patient with traumatic atlantoaxial joint disruption. J Clin Neurosci 17:672-673, 2010

24. Goel A, Kulkarni AG: Mobile and reducible atlantoaxial dislocation in presence of occipitalized atlas: report on treatment of eight cases by direct lateral mass plate and screw fixation. Spine (Phila Pa 1976) 29:E520-E523, 2004

25. Goel A, Kulkarni AG, Sharma P: Reduction of fixed atlantoaxial dislocation in 24 cases: technical note. J Neurosurg Spine 2:505-509, 2005

26. Goel A, Laheri VK: Plate and screw fixation for atlanto-axial dislocation. Acta Neurochir (Wien) 129:47-53, 1994

27. Goel A, Pareikh S, Sharma P: Atlantoaxial joint distraction for treatment of basilar invagination secondary to rheumatoid arthritis. Neurol India 53:238-240, 2005

28. Goel A, Shah A: Atlantoaxial facet locking: treatment by facet manipulation and fixation. Experience in 14 cases. J Neurosurg Spine 14:3-9, 2011

29. Goel A, Shah A: Facetal distraction as treatment for singleand multilevel cervical spondylotic radiculopathy and myelopathy: a preliminary report. J Neurosurg Spine 14:689696, 2011

30. Goel A, Shah A: Reversal of longstanding musculoskeletal changes in basilar invagination after surgical decompression and stabilization. J Neurosurg Spine 10:220-227, 2009

31. Goel A, Shah A, Gupta SR: Craniovertebral instability due to degenerative osteoarthritis of the atlantoaxial joints: analysis of the management of 108 cases. J Neurosurg Spine 12:592-601, 2010

32. Goel A, Shah A, Jadhav M, Nama S: Distraction of facets with intraarticular spacers as treatment for lumbar canal stenosis: report on a preliminary experience with 21 cases. $\mathbf{J}$ Neurosurg Spine 19:672-677, 2013

33. Goel A, Shah A, Rajan S: Vertical mobile and reducible atlantoaxial dislocation. Clinical article. J Neurosurg Spine 11:9-14, 2009

34. Goel A, Sharma P: Craniovertebral junction realignment for the treatment of basilar invagination with syringomyelia: preliminary report of 12 cases. Neurol Med Chir (Tokyo) 45:512-518, 2005

35. Goel A, Sharma P: Craniovertebral realignment for basilar invagination and atlantoaxial dislocation secondary to rheumatoid arthritis. Neurol India 52:338-341, 2004

36. Kothari M, Goel A: Transatlantic odonto-occipital listhesis: the so-called basilar invagination. Neurol India 55:6-7, 2007

\section{INCLUDE WHEN CITING}

Published online September 4, 2015; DOI: 10.3171/2015.3.SPINE15233.

(c)AANS, 2015 


\section{Sacroiliac joint fusion}

TO THE EDITOR: We compliment Zaidi et al. ${ }^{8}$ on their independent and well-reported review of open and minimally invasive sacroiliac (SI) joint fusion (Zaidi HA, Montoure AJ, Dickman CA: Surgical and clinical efficacy of sacroiliac joint fusion: a systematic review of the literature. J Neurosurg Spine 23:59-66, July 2015). We are writing to highlight a few aspects of the review. First, in our prospective multicenter clinical trial, 53 adverse events occurred in 34 of 94 patients. ${ }^{1}$ This trial was different from prior reports in that it asked investigators to follow an international clinical trial standard (ISO 10993:2011), which requires reporting of all adverse events, not just those related to surgery. Of the adverse events reported, only 6 were severe and only 1 involved the surgical site itself (a wound infection). None were related to the iFuse implant. The 56\% rate of adverse events is therefore an apples-tooranges comparison to other cited studies, as most other studies only selectively reported adverse events.

Second, since May 2014 (when Dr. Zaidi and colleagues' article was submitted), several relevant studies have been published. ${ }^{2-7}$ First, two groups reported 4.5-year ${ }^{6}$ and 5 -year ${ }^{3}$ follow-ups. In the 5 -year ${ }^{3}$ follow-up study, bridging bone across the SI joint was reported in most cases. Second, a quantitative comparison of open and minimally invasive SI joint fusion showed statistically significant and clinically important differences in both process parameters (procedure time, blood loss, and hospital length of stay) and pain responses in support of minimally invasive fusion. ${ }^{5}$ Finally, INSITE, a landmark prospective, multicenter randomized clinical trial of patients treated with minimally invasive SI joint fusion compared with those receiving nonsurgical treatment, showed that subjects with chronic SI joint dysfunction who underwent surgery had substantially greater improvements in pain, disability, and quality of life outcomes at 6 months, with no statistically significant differences in adverse event rates between the two groups. ${ }^{7}$ This last publication confirms that SI joint pain can be successfully diagnosed and treated.

Thanks again to Dr. Zaidi and his coauthors for the current systematic review, and we look forward to additional prospective and retrospective studies focused on the treatment of SI joint symptoms to better understand the diagnosis, treatment safety, and treatment efficacy.

\section{Daniel Cher, MD}

SI-BONE, Inc., San Jose, CA

\section{DISCLOSURE}

Dr. Cher reports being an employee of SI-BONE.

\section{References}

1. Duhon B, Cher D, Wine K, Lockstadt H, Kovalsky D, Soo CL: Safety and 6-month effectiveness of minimally invasive sacroiliac joint fusion: a prospective study. Med Devices Evid Res 6:219-229, 2013

2. Gaetani P, Miotti D, Risso A, Bettaglio R, Bongetta D, Custodi V, et al: Percutaneous arthrodesis of sacro-iliac joint: a pilot study. J Neurosurg Sci 57:297-301, 2013

3. Rudolf L, Capobianco R: Five-year clinical and radiographic outcomes after minimally invasive sacroiliac joint fusion using triangular implants. Open Orthop J 8:375-383, 2014

4. Schroeder JE, Cunningham ME, Ross T, Boachie-Adjei O: Early results of sacro-iliac joint fixation following long fusion to the sacrum in adult spine deformity. HSS J 10:30-35, 2014

5. Smith AG, Capobianco R, Cher D, Rudolf L, Sachs D, Gundanna M, et al: Open versus minimally invasive sacroiliac joint fusion: a multi-center comparison of perioperative measures and clinical outcomes. Ann Surg Innov Res 7:14, 2013

6. Vanaclocha V, Verdu-Lopez F, Sanchez-Pardo M, GonzalbesEsterelles L: Minimally invasive sacroiliac joint arthrodesis: experience in a prospective series with 24 patients. J Spine 3:185, 2014

7. Whang P, Cher D, Polly D, Frank C, Lockstadt H, Glaser J, et al: Sacroiliac joint fusion using triangular titanium implants vs. non-surgical management: six-month outcomes from a prospective randomized controlled trial. Int J Spine Surg 9:6, 2015

8. Zaidi HA, Montoure AJ, Dickman CA: Surgical and clinical efficacy of sacroiliac joint fusion: a systematic review of the literature. J Neurosurg Spine 23:59-66, 2015

\section{Response}

We thank Dr. Cher for his thoughtful review of our article. Although the results of INSITE ${ }^{1}$ seem to demonstrate short-term efficacy of SI joint fusion compared with conservative management in a prospective randomized group, more than 6 months of follow-up and a larger cohort of patients are needed to truly validate these findings. Additionally, radiographic evidence of fusion after intervention was not published with the INSITE results. Furthermore, the description of clinical decision making in this article may not accurately reflect actual surgical practice. Patient selection is key to effectively treating SI joint pain.

In our practice, we find that patients suffering from SI joint pain typically have multiple pain generators and that their symptoms commonly overlap with other forms of mechanical back pain. Identifying patients whose SI joint pain is the primary pain source is difficult and limited by the diagnostic tools and clinical criteria currently available. For these reasons, many patients are at risk of undergoing unnecessary surgical SI joint fusion. Further studies are needed to develop an effective diagnosis and treatment strategy for this complex set of patients.

\section{Hasan A. Zaidi, MD \\ Curtis A. Dickman, MD \\ On behalf of all authors \\ Barrow Neurological Institute, Phoenix, AZ}

\section{Reference}

1. Whang P, Cher D, Polly D, Frank C, Lockstadt H, Glaser J, et al: Sacroiliac joint fusion using triangular titanium implants vs. non-surgical management: six-month outcomes from a prospective randomized controlled trial. Int J Spine Surg 9:6, 2015

\section{INCLUDE WHEN CITING}

Published online August 28, 2015; DOI: 10.3171/2015.4.SPINE15410.

CAANS, 2015 